\title{
Behavior of AFRP Composite and its Practical Aspects in the Invigoration of Structural and Materialistic Properties of Corroded SHTS
}

\author{
Nabajyoti Modak, Durlab Das, R. Vinodh Kumar
}

\begin{abstract}
The usage of effective composite materials currently became a regular trend in different field of industrial works and production factories. Composite materials being having a property of fulfilling more than one property simultaneously became an effective material recently in practical life. Fiber Reinforced Polymer (FRP) composite, due to its low weight, high stiffness huge load carrying capacity, corrosion less property, it became a friendly material for different engineering purposes where materials get include. In the world of Civil Engineering, Aeronautical Engineering, Mechanical Engineering and Automobile Engineering, currently the trend of FRP became very familiar for increasing the strength of materials for different properties and from different orientations. Strengthening and retrofitting of any structural elements become mandatory when the structure gets distressed due to several loading and aging effects. This research paper contains the concept of Aramid Fiber Reinforced Polymer (AFRP) composite and its application in the strengthening of corroded Steel Hollow Tubular Sections (SHTS). The improvement in the properties of SHTS after applying AFRP is discussed in this research content and its polymerization effect on strengthening. To establish a comparison on the recent research trend in this area, a special way of retrofication scheme was involved in this investigation, by following a practice of spiral or helical wrapping of AFRP to achieve a continues stiffness with a uniform unity across the height of the column. To analyze the proposed strengthening scheme, a comparative study has been done with respect to the traditional approach. A series of experimental investigation was done to come up with the result and later a brief discussion has been done regarding the usage of AFRP in different fields of Engineering. Totally 21 samples were casted both in horizontal and spiral jacketing and tested experimentally under axial compressive load by sustaining several parameters to observe the variation in the change of the properties of SHTS to verify the axial load carrying capacity along with the stiffness and Young's modulus. The experimental investigation showed that there is a remarkable improvement in the properties of AFRP strengthened specimens with respect to different parameters after the application AFRP and the effect of its
\end{abstract}

Revised Manuscript Received on December 30, 2019.

* Correspondence Author

Mr. Nabajyoti Modak*, Assistant Professor, Department of Civil Engineering, Anand Institute of Higher Technology, Chennai, Tamil Nadu, India. Email ID: modaknabajyoti84@gmail.com

Mr. Durlab Das, Completed M. Tech in Aeronautical Engineering, Hindustan Institute of Technology and Science, Chennai, Tamil Nadu, India. Email ID: durlav1993@gmail.com

Mr. R Vinodh Kumar, Assistant Professor, Department of Civil Engineering,, Meenakshi College of Engineering, Chennai, Tamil Nadu. Email: er.r.rvinodhkumar@gmail.com

(C) The Authors. Published by Blue Eyes Intelligence Engineering and Sciences Publication (BEIESP). This is an open access article under the CC BY-NC-ND license (http://creativecommons.org/licenses/by-nc-nd/4.0/) polymerization with the bonding agent. Thus after the strengthening of column specimens with AFRP, the overall increment in the load ringing capacity of the SHTS was $23.27 \%$ and also the proposed scheme of spiral wrapping provided a superior result as compared to the traditional method of horizontal stripping.

Index Terms: AFRP, Axial load, Buckling, Elasticity, SHTS, Stiffness, Strengthening

\section{INTRODUCTION}

Strengthening and retrofitting of a structural assembly or any structural element is a process by which we can increase the life span of a structure by supporting the structure additionally from any external sources. In construction industries, this type of work is very familiar across the globe. Some of the prime reasons for the deterioration of any structures are continuous loading effect, aging of structures, weathering effect and so on. To increase the life span of structure, the weak zone as well as the load and non-load bearing elements of the structure should be detected and have to retrofit or replace those elements for making the structure serviceable again. The old traditional methods for executing such work are somewhat difficult as they need more time, huge man power, high weight instrumentations and more cost as well. The introduction of FRP application in such types of works may reduce all those problems and can able to make the work process easy with different beneficial outcomes such as no additional weight, non-corrosive, high stiffness, well durable, chemically inactive, immense load carrying capacity, and ease in application. In production factories, the usage of FRP enables to produce high ductile and durable materials with less weight with good aesthetic view. The use of FRP in the pressure vessels strengthening for aeronautical and aerospace engineering is quite noticeable and lot of research works are going on in this field. Thus FRP became an agile material in different industries and research fields for its enormous beneficial estates. This paper broaches about the strengthening of corroded SHTS by introducing AFRP and its application in other fields of engineering. Steel structure owing to have its high ductility and high load bearing capacity with respect to cross-section, is highly preferred by the designers for quick constructions. But when exposed to open environment, steel used to get corroded easily due to the oxidation with oxygen from open atmosphere. Thus very shortly the steel structures get deteriorated even after applying high quality paint as well. Thus the conventional methods of retrofitting and replacement of any structural elements become more difficult for steel structures resulting huge expense. 


\section{Behavior of AFRP Composite and its Practical Aspects in the Invigoration of Structural and Materialistic Properties of Corroded SHTS}

To omit all those difficulties the usage of high modulus AFRP for strengthening steel structures are quite worthy and easy. Various researchers did numerous experimental and analytical investigations on the strengthening effect of different FRPs in hollow tubular sections of different dimensions by following several parameters. Most commonly the use of Glass Fiber Reinforced Polymer (GFRP) and Carbon Fiber Reinforced Polymer (CFRP) were prominent. Sreedhar Kalavagunta et.al [1] did theoretical and experimental investigation and came up with a proposed design of axially loaded CFRP retrofitted cold formed steel lipped channel sections. The elastic modulus of the composite section along with CFRP strip by neglecting the layer of bonding agent was expressed by them. The test result that was revealed from the experimental investigation shows that the strength of the section is increase by about $16.75 \%$. Later, the results were compared with AISI-2007 and EC3-EN1993-1-3:2006. According to their research conclusion, it has been said that the ultimate axial strength depends on the bonding of the CFRP strip with the steel plates.

Nabajyoti Modak et.al [2] also performed an experimental investigation on corroded circular hollow sections by applying AFRP. The corrosion done in that experimental work was an artificial corrosion by using Rusty-3000. A Special technique of wrapping was followed for retrofitting the column samples with AFRP. The percentage of the corrosion was determined by the process of weight reduction method. Conventionally, the wrapping used to done by horizontal strips by maintaining some spacing in between them, but they followed a different way of spiral wrapping scheme for strengthening the hollow tubular sections. The result showed significant enhancements in the properties of column samples after retrofitting with AFRP. They also concluded that the increase in the number of layers of FRP increases the strength of the specimens. Approximately, $34.27 \%$ of strength has been increased after the application of three layers of AFRP.

To study the behavior of concrete filled steel tubular columns, J. Zeghiche et.al [3] performed an experimental investigation on 27 concrete filled tubular steel columns by following different parameters such as slenderness ratio, types of loadings both axially and eccentrically including double and single curvature bending and compressive strength of concrete core. The ultimate conclusion made after all those steps were the increment in the column slenderness decreases the load carrying capacity of the composite columns. Zhong Tao et.al [4] did a nonlinear investigation by using ABAQUS designed stiffened square stub columns under axial compressive load. The model proposed in their analysis was stiffened thin walled steel tubular columns. The results obtained from the forecast and test came close with respect to critical strength and load-deflection curves. By using their modeling they inspected and conferred the behavior of the column. They also illuminated the necessary firmness and the limit of width-thickness ratio for the stiffeners of their proposed model. With the help of the prevailing design codes, the achievability was also discussed to expect the load bearing capabilities of the stiffened composite columns.

K. Abedi et.al [5] recommended an innovative column unit for large span bridges and tall buildings. The important characteristic of the suggested steel section was interior longitudinal symmetric stiffeners. The section was advocated by seeing the prime parameters for load bearing capacity such as the bonding of concrete with the internal surface of the column, local buckling, and strength of the steel tubes with the creep of the concrete as well. The projected models of the column specimens were analyzed under axial and cyclic loading and later the results were verified with finite element modeling with plentiful analyses on dissimilar materialistic and structural properties. The proposed innovative section that was recommended showed a better load carrying capacity under the both types of loadings. Kambiz Narmashiri et.al [6] carried out an experimental and analytical research on the strengthening of steel I-beams in the shear zone by using CFRP strips. The exploration was carried out to observe the variation in the enhancement of I-beams by following two different parameters of CFRP application areas and the attachment of CFRP strips on one or both faces of the web of the I-beams. The results of their research work implies that, the application of CFRP on web of I-beam can able to increase around 51\% of the strength of the beam by reducing the usage of CFRP in shear.

$\mathrm{X}$. Wang et.al [7] did an examination on self-strengthening fiber reinforced pressure vessel by instigating metallic liners. They determined a self-strengthening pressure to undergo an elastic buckle in the metallic lining under hydrostatic pressure and also obtained a perfect ratio of the vessel's volume and weight. Thus they improved the gas-tightness and the lassitude strength of the fiber reinforced pressure vessel. They implemented automatic dynamic increment nonlinear finite element analysis and wrapped up by determining the influence of thermal load on the vessel. V. L. Kadlag et.al [8] did an analysis on the application of Fiber Reinforced Polymer composites in the automotive Industry. They attempted to make a review on the application of FRP in the different sectors of automotive engineering and industry. As the different materials and parts of automotive systems are of light weight but used to carry huge load, compare to other composite constituents like steel or aluminum, application of FRP may provide huge impact factor in improving the materialistic properties of different materials in automotive industry [8]. They also appraised that, the cost of production by using some of the FRPs is less than using other novel or inert metallic elements. Medhavi Sinha et.al [9] performed a burst investigation and also designed a CFRP confined composite pressure vessel by providing various fiber orientations. Composite pressure vessels are rummage-sale in different types of engineering areas such as aeronautical engineering, chemical engineering, automobile engineering [9]. By using the Finite element analysis centered software ANSYS 11 they analyzed and designed a composite pressure vessel of four layered CFRP with two parameters of Hoop and Spiral wrapping. In the case of spiral wrapping, they followed a fiber orientation of $\pm 25^{\circ}$, $\pm 35^{\circ}, \pm 45^{\circ}, \pm 55^{\circ}, \pm 65^{\circ}$ and $\pm 75^{\circ}$. After scheming, they examined the burst pressure on the pressure vessel with respect to the principles of Tsai-Wu failure.

Sarada Prasad Parida et.al [10] originated up a design of

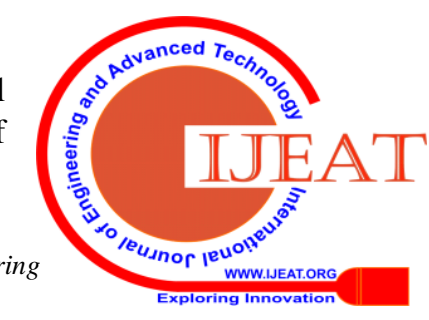


profuse enclosed veneered composite pressure vessel. The foremost objective of their research was to accomplish a finite element analysis on glass fiber reinforced pressure vessel with epoxy resin in order to triumph a laminated thick walled composite pressure vessel. They analyzed the pressure vessel under altered kind of loadings for the procurement of various stresses and strains from different orientation of strengthening involvement by using the Lame's theory. Later the results gained were further paralleled and scrutinized with the results of ordinary steel walled LPG pressure vessel and publicized that, the usage of composite pressure vessels for ordinary steel LPG may provide better upshot in resisting the internal stresses for both radial and circumferential. An explorative investigation was done by Chao Hou et.al [11] to study the behavior and effect of loading and corrosion with chloride as well on concrete filled steel tubular square sections. They performed a finite element analysis on the load-deflection behavior of the column samples. At last they discussed about the benefit of composite actions of steel and concrete for the better outcome and making the section more ductile to subject more loads.

In this research content the application and benefit of AFRP has been discussed along with experimental investigation to strengthen hollow circular steel section and how it improves the properties of the composite section of steel and AFRP with the polymerization effect. In the past activities regarding retrofitting of structures with FRP it has been noticed that the use of CFRP and GFRP is prominent. Thus to see the variation in the properties AFRP has been selected in this experimental work.

\section{MATERIALS USED}

\section{A. Steel Hollow Tubular Sections (SHTS)}

Short columns of Steel Hollow Tubular Sections were used in this research work as per the Indian Standard 1164 1998, Steel Tubes for Structural Purpose [10]. The height of the column samples were taken as $600 \mathrm{~mm}$ with external diameter of $88.9 \mathrm{~mm}$ and thickness $3.2 \mathrm{~mm}$. According to IS: 1164 1998, the section is light and the radius of gyration of this section is $30.3 \mathrm{~mm}$. Thus the slenderness ratio of the column samples were found as 19.80, which can be grouped as short columns. The yield strength of the column samples were $250 \mathrm{~N} / \mathrm{mm}^{2}$ as given by the producer.

\section{B. Aramid Fiber Reinforced Polymer (AFRP)}

Aramid fiber Reinforced Polymer (AFRP) used in this experimental work was golden yellow color fiber polymer with elastic modulus of $242 \mathrm{kN} / \mathrm{mm}^{2}$ and the tensile strength of $3948 \mathrm{~N} / \mathrm{mm}^{2}$ as provided by the manufacturer. The AFRP used for fabrication was of 480 GSM (gram per square meter), density of $1.78 \mathrm{~g} / \mathrm{cm}^{2}$ and thickness of $3.2 \mathrm{~mm}$. It is a high heat resistant and durable fiber which can able to resist severe abrasion effect from the external source and also inert in chemical reactions. Thus the use of AFRP in retrofitting the column samples was quite easy and friendly throughout the experimental work. As the wrapping system followed in this experimental work is exceptional bidirectional AFRP was preferred. The thickness chosen for the AFRP sheet easily got fitted in any profile with the bonding agent. Thus the application of AFRP in retrofitting work was quite smooth.

\section{Matrix Materials (Epoxy Resin and Hardener D)}

Epoxy adhesives is a prime bonding agent and also well known as any structural bonding agent is a high quality adhesive with good polymerization effect when mixed with any suitable promoter or hardener. Some of the epoxy or other types of resin such as polyester may often need catalyst to promote the polymerization effect. The epoxy is a unique type of resin which gives a best bonding strength when gets blend with a suitable hardener in a proper ratio. The bonding agent used in this experimental investigation was Epoxy Resin 520, which is a conservative viscosity liquid epoxy resign. After full curing stage, it gives a high strength and good abrasion resistant property. The properties of the epoxy resin of this work as mentioned by the manufacturer are given in the Table I.

Table I. Estates of epoxy resin and hardener D

\begin{tabular}{|c|c|c|}
\hline Properties & $\begin{array}{c}\text { Epoxy Resin } \\
\mathbf{5 2 0}\end{array}$ & Hardener D \\
\hline Category & $\begin{array}{c}\text { Solvent } \\
\text { modified resin }\end{array}$ & Polyamide \\
\hline Look & Colorless liquid & Clear liquid \\
\hline $\begin{array}{c}\text { Viscosity at } \\
27 \text { C }\end{array}$ & $650+/-100$ & $650+/-100$ \\
\hline Specific gravity & $1.15-1.21$ & $0.96 \pm 0.1$ \\
\hline Container life & 2 hours & - \\
\hline $\begin{array}{c}\text { Storage } \\
\text { constancy }\end{array}$ & 1 year & $5-6$ months \\
\hline
\end{tabular}

\section{EXPERIMENMTAL PROCEDURE}

\section{A. Corrosion of Samples}

As the natural process of corrosion takes a long time, to increase the rate of corrosion, an artificial way of corrosion system was followed in this experimental work. There are lot of artificial corrosion process in which different chemical may be used to increase the oxidation rate of iron present in steel. In this research work a very easy and fast process of corrosion method was adopted by using Rusty - 3000 [2]. Rusty - 3000 is a chemical mix of vinegar (acetic acid) and hydrogen peroxide in a ratio of 1:7 by volume that is one part of vinegar with seven part of hydrogen peroxide and 15 to $20 \mathrm{gm}$ of table salt (sodium chloride). The process of corrosion is very simple, first the samples were dipped in normal vinegar for 20 to 30 minutes and then the samples were allowed to get dry for another 30 minutes in room temperature. Then the samples were dipped in to the solution of Rusty - 3000 for initiating the corrosion in a fast rate. The corrosion process was continued up to when the weight of the samples starts reducing. Then the corrosion measure was found out by weight reduction method [2]. The average of corrosion percentage of the samples was $1.53 \%$. Figure 1 shows one sample of corroded specimen. Strengthening or retrofication can able to immense the load carrying capacity of any structural elements up to a certain extent.

If the rate of deterioration is too high the strengthening process won't help any

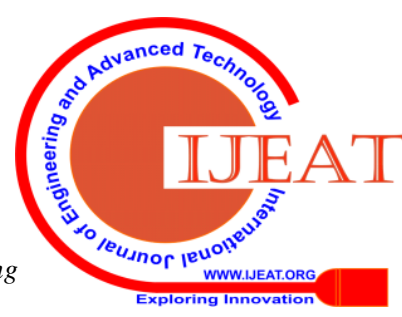


Behavior of AFRP Composite and its Practical Aspects in the Invigoration of Structural and Materialistic Properties of Corroded SHTS

structural elements to regain its original estate to become serviceable again. The rate of corrosion was controlled in such a way that, the weight reduction may not change the entire physical estates of the column samples.

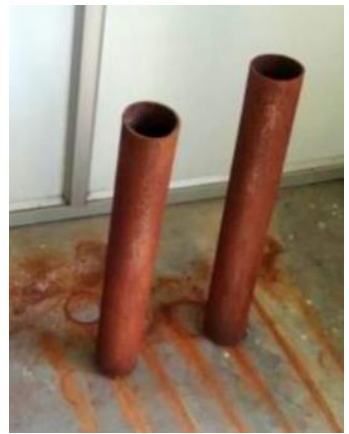

Fig.1. Samples with corrosion.

\section{B. Bonding of AFRP Composite}

After the corrosion, the column samples were cleaned thoroughly across their surfaces by using sand paper to remove the rusts on the surface. Then to avoid the surface impurities, acetone was applied on the column's surface by using clean and soft cotton cloth. Once the surface preparation was over then the marking was done in the AFRP sheet according to the required shape and strip by using marker. After the cleaning process of the specimens, to avoid galvanic corrosion a light semi-transparent GFRP mat was used that will maintain a cover in between the AFRP with the steel surface. Tough AFRP basically is an inert material, but due to polymerization effect it may cause a reason of corrosion and the heat generated during polymerization also may cause some change in the materialistic properties of the steel columns, thus to avoid those obstacles a light cover of non-load bearing GFRP mat was provided. AFRP wrapping was done in two different ways to study the variation in applying the AFRP in load carrying capacity and other physical properties of the composite section as well. The first way of applying AFRP was in spiral wrapping of width $60 \mathrm{~mm}$ with an approximate spacing of $40 \mathrm{~mm}$ in between the strips. On the other hand, the second set of samples was casted with horizontal wrapping of $60 \mathrm{~mm}$ strip width with a midway spacing of $18 \mathrm{~mm}$ center to center. To observe the consequence of number of AFRP layers, three layers of wrapping in both the cases were done gradually in one, two and three layers separately. For wrapping with AFRP, the sheet was cut in to perfect size and shape according to the width and marking then the blend of epoxy resin and hardener was applied as bonding agent. For obtaining a perfect polymerization the ratio of mixing given by the manufacturer was 10 (epoxy) : 1 (hardener) by volume. Totally 18 samples were wrapped for strengthening of which 9 samples with horizontal strip and 9 samples of spiral stripping with all of one, two and three layers. In case of overlapping, $50 \mathrm{~mm}$ overlapping length was followed. The specimens were leveled with different designations for further identification as followed in Table II.

\begin{tabular}{|c|c|}
\hline Designations & Sample quantity \\
\hline CC & Control Sample \\
\hline SHTS-HS-1L & $\begin{array}{c}\text { Horizontal strip of 1 } \\
\text { layer }\end{array}$ \\
\hline SHTS-HS-2L & $\begin{array}{c}\text { Horizontal strip of } 2 \\
\text { layers }\end{array}$ \\
\hline SHTS-HS-3L & $\begin{array}{c}\text { Horizontal strip of 3 } \\
\text { layers }\end{array}$ \\
\hline SHTS-SP-1L & Spiral strip of 1 layer \\
\hline SHTS-SP-2L & Spiral strip of 2 layers \\
\hline SHTS-SP-3L & Spiral strip of 3 layers \\
\hline
\end{tabular}

Further the column samples were air cured in room temperature and then tested after one week for determining the result.

\section{Setup for Experiment}

To observe the materialistic properties of the short columns, the samples were tested under Universal Testing Machine (UTM) of capacity $1000 \mathrm{kN}$. The specimens were fitted in the UTM with dial gauge to observe the vertical deformation along with the cross head movement of the loading system. Before mounting the column samples in UTM the base and top level of the specimens were checked by using sprit level. Demountable Mechanical (DeMech) Strain Gauge of gauge length $200 \mathrm{~mm}$ was used to determine the strain values for each and every sample. The behavior and the failure mode of all the specimens were studied by applying gradual axial load slowly from $10 \mathrm{kN}$. To study the entire behavior of the column samples the specimens were loaded up to their failure modes.

\section{RESULTS AND DISCUSSIONS}

\section{A. Failure Modes of the Column Samples.}

The overall load carrying capacity of the specimens was increased after retrofitting with AFRP with the increment in the number of layers. The ultimate load carrying capacity, percentage in increase of load bearing capability and other information that was obtained from the experimental results is shown in the Table III. below.

Table III. Experimental outcomes

\begin{tabular}{|c|c|c|l|l|}
\hline $\begin{array}{l}\text { Sl. } \\
\text { No. }\end{array}$ & $\begin{array}{c}\text { Column } \\
\text { Specimens }\end{array}$ & $\begin{array}{l}\text { Ultimat } \\
\text { e Load } \\
\mathbf{( k N )}\end{array}$ & $\begin{array}{l}\text { Deflecti } \\
\text { on at } \\
\text { Peak } \\
\text { Load } \\
\text { (mm) }\end{array}$ & $\begin{array}{l}\text { Percent } \\
\text { age } \\
\text { Increas } \\
\text { e }\end{array}$ \\
\hline 1 & CC (1) & $\mathbf{3 1 8}$ & $\mathbf{7 . 7 2}$ & - \\
\hline 2 & CC (2) & 312 & 7.79 & - \\
\hline 3 & CC (3) & 304 & 7.83 & - \\
\hline 4 & $\begin{array}{c}\text { SHTS-HS-1 } \\
\text { L (1) }\end{array}$ & $\mathbf{3 3 7}$ & $\mathbf{7 . 3 3}$ & $\mathbf{5 . 9 7}$ \\
\hline 5 & $\begin{array}{c}\text { SHTS-HS-1 } \\
\text { L (2) }\end{array}$ & 329 & 7.35 & 3.46 \\
\hline 6 & $\begin{array}{c}\text { SHTS-HS-1 } \\
\text { L (3) }\end{array}$ & 335 & 7.40 & 5.35 \\
\hline 7 & $\begin{array}{c}\text { SHTS-HS-2 } \\
\text { L (1) }\end{array}$ & 352 & 7.29 & 10.69 \\
\hline
\end{tabular}

Table II. Leveling of columns 


\begin{tabular}{|c|c|c|c|c|}
\hline 8 & $\begin{array}{c}\text { SHTS-HS-2 } \\
\text { L (2) }\end{array}$ & $\mathbf{3 5 8}$ & $\mathbf{7 . 2 4}$ & $\mathbf{1 2 . 5 8}$ \\
\hline 9 & $\begin{array}{c}\text { SHTS-HS-2 } \\
\text { L (3) }\end{array}$ & 356 & 7.28 & 11.95 \\
\hline 10 & $\begin{array}{c}\text { SHTS-HS-3 } \\
\text { L (1) }\end{array}$ & $\mathbf{3 7 6}$ & $\mathbf{7 . 0 6}$ & $\mathbf{1 8 . 2 4}$ \\
\hline 11 & $\begin{array}{c}\text { SHTS-HS-3 } \\
\text { L (2) }\end{array}$ & 371 & 7.10 & 16.67 \\
\hline 12 & $\begin{array}{c}\text { SHTS-HS-3 } \\
\text { L (3) }\end{array}$ & 359 & 7.13 & 12.89 \\
\hline 13 & $\begin{array}{c}\text { SHTS-SP-1 } \\
\text { L (1) }\end{array}$ & 351 & 7.21 & 10.38 \\
\hline 14 & $\begin{array}{c}\text { SHTS-SP-1 } \\
\text { L (2) }\end{array}$ & 348 & 7.26 & 9.43 \\
\hline 15 & $\begin{array}{c}\text { SHTS-SP-1 } \\
\text { L (3) }\end{array}$ & $\mathbf{3 5 3}$ & $\mathbf{7 . 1 9}$ & $\mathbf{1 1 . 0 0}$ \\
\hline 16 & $\begin{array}{c}\text { SHTS-SP-2 } \\
\text { L (1) }\end{array}$ & 369 & 6.98 & 16.04 \\
\hline 17 & $\begin{array}{c}\text { SHTS-SP-2 } \\
\text { L (2) }\end{array}$ & $\mathbf{3 7 5}$ & $\mathbf{6 . 9 4}$ & $\mathbf{1 7 . 9 0}$ \\
\hline 18 & $\begin{array}{c}\text { SHTS-SP-2 } \\
\text { L (3) }\end{array}$ & 365 & 7.01 & 14.78 \\
\hline 19 & $\begin{array}{c}\text { SHTS-SP-3 } \\
\text { L (1) }\end{array}$ & $\mathbf{3 9 2}$ & $\mathbf{6 . 7 0}$ & $\mathbf{2 3 . 2 7}$ \\
\hline 20 & $\begin{array}{c}\text { SHTS-SP-3 } \\
\text { L (2) }\end{array}$ & 378 & 6.85 & 18.87 \\
\hline 21 & $\begin{array}{c}\text { SHTS-SP-3 (3) } \\
\text { LHS }\end{array}$ & 389 & 6.92 & 22.33 \\
\hline
\end{tabular}

deflection of $7.24 \mathrm{~mm}$ at the highest load. The specimens of SHTS-HS-2L failed due to crushing load but the local buckling at this time was quite less as compared to the SHTS-HS-1L. This is due to the high stiffness provided by the polymerization of AFRP with the matrix material. In this case, a fiber fracture was seen at the bottom of the specimen just before achieving the failure load and when the loading was continued beyond the ultimate load, the bottom most fiber strip got de-touched due to huge buckling of the column foot. The failure mode of SHTS-HS-2L is shown in the Figure 4. The ultimate load carrying capacity of SHTS-HS-3L was $376 \mathrm{kN}$ with a maximum deflection of $7.06 \mathrm{~mm}$. here due to the enormous stiffness of the AFRP bonding, the column specimens were able to take a more load as compared to SHTS-HS-1L and SHTS-HS-2L. In this case, the buckling of the column specimens was less even after crossing the ultimate load also. The firmness that was provided due to the AFRP bonding helps the column samples to get intact and to bear more axial load. Figure 5. shows the failure pattern of the SHTS-HS-3L.

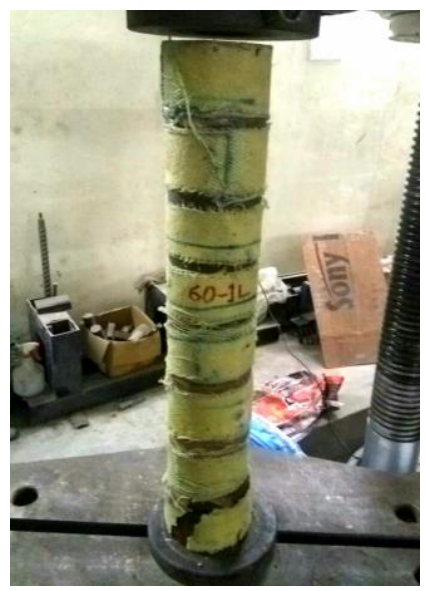

Fig. 3. Failure mode of SHTS-HS-1L specimen.

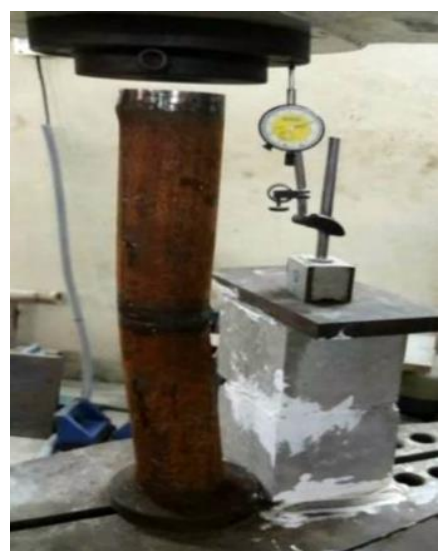

Fig. 2. Failure mode of control sample

The failure pattern of the SHTS-HS-1L is shown in the Figure 3. which explains the patterns of buckling in the column sample along with the Failure of AFRP. The ultimate load carrying capacity for SHTS-HS-1L was $337 \mathrm{kN}$ with a maximum deflection of $7.33 \mathrm{~mm}$. In this case also the column specimen was failed due to crushing strength of the gradually applied axial load. In the mid-way of the experiment, the column specimen of SHTS-HS-1L was start failing with local buckling and with fiber rapture at the bottom of the column with a metallic sound. The ultimate load carrying capacity of SHTS-HS-2L was found as $358 \mathrm{kN}$ with a maximum

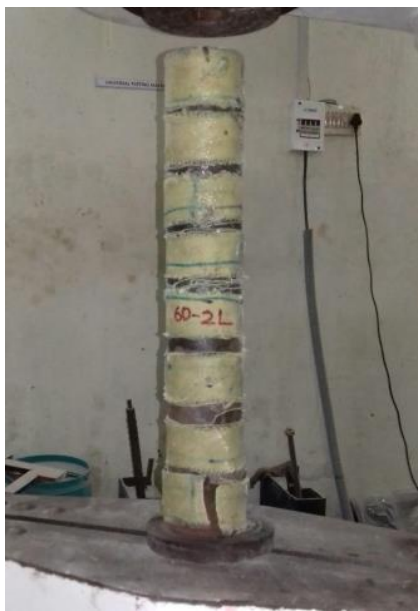

Fig.4. Failure mode of SHTS-HS-2L 

Properties of Corroded SHTS

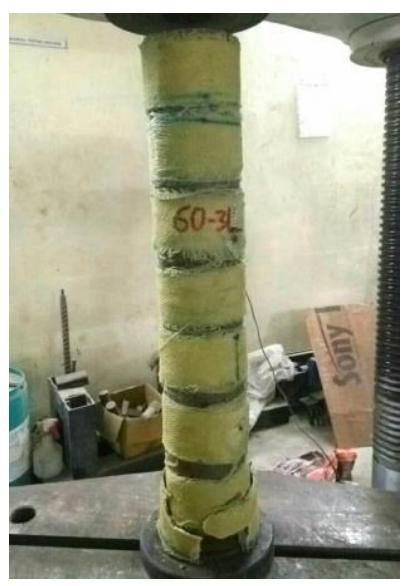

Fig. 5. Failure mode of SHTS-HS-3L

The technique of spiral wrapping was a unique idea of retrofication for achieving a monolithic wrapping to achieve continues strength across the entire length of the specimens. Thus it provides a uniform stiffness without any discontinuation unlike those horizontal wrappings. The load carrying capacity of SHTS-SP-1L was found as $353 \mathrm{kN}$ and the deflection at the peak load was $7.19 \mathrm{~mm}$. The column sample was failed due to the humiliating load with a little bend in the mid portion and a small rupture in AFRP in the top portion of the column. The failure mode of the SHTS-SP-1L is visualized in Figure 6. In the case of SHTS-SP-2L the ultimate load carrying capacity was $375 \mathrm{kN}$ and the deflection of the member at the peak load was $6.94 \mathrm{~mm}$. In the case of SHTS-SP-2L, it has been observed that, the column sample underwent with a minimum local buckling due to the enormous stiffness provided by continues wrapping scheme of AFRP. The catastrophic pattern of SHTS-SP-2L is given in the Figure 7. The ultimate load carrying capacity of the SHTS-SP-3L was found as $392 \mathrm{kN}$ and the maximum deflection at the peak load was found as $6.70 \mathrm{~mm}$. The strength of this category was immensely increased due to the strong firmness provided by the intact of three layers of AFRP in continues spiral wrapping scheme. No such buckling was observed externally rather a small buckling in the inward surface of the specimen was noticed as the firmness leads the column specimen to fail by buckling in the inward face. A light bend was observed in the sample after crossing the ultimate load to see the mode of failure. Figure 8. shows the failure mode of SHTS-SP-3L.

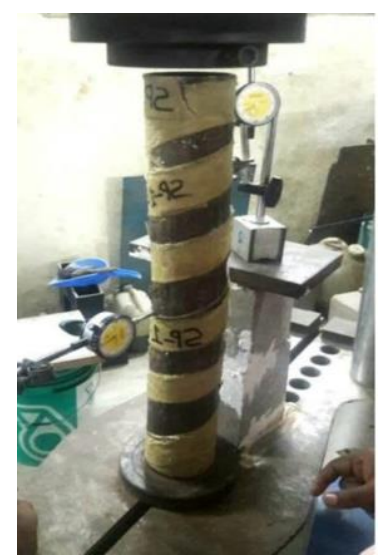

Fig. 6. Failure mode of SHTS-SP-1L

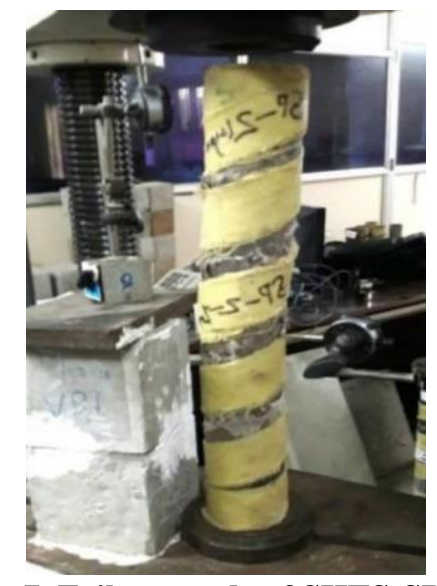

Fig. 7. Failure mode of SHTS-SP-2L

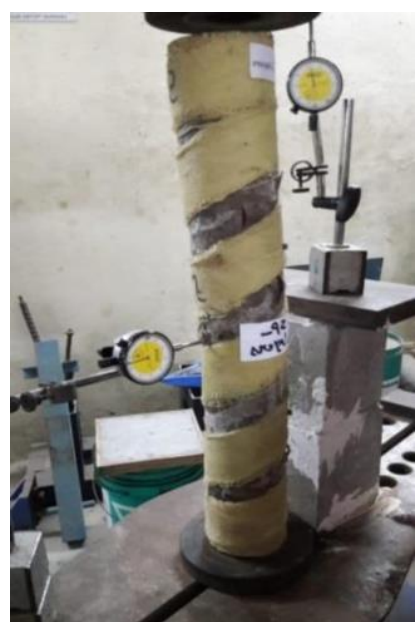

Fig. 8. Failure mode of SHTS-SP-3L

\section{B. Stiffness Property in Terms of Load and Displacement}

For verifying the stiffness obtained by the AFRP wrapping and to study the load deflection behavior, a graph has been plotted by taking the values of Load along ' $\mathrm{Y}$ ' axis and Deflection along ' $\mathrm{X}$ ' axis. Figure 9. shows the variation of load versus deflection. From this diagram it can be observed that, the deflections of the wrapped specimens were reduced even after reaching at high loads. This indicates the stiffness was increasing due to the wrapping of AFRP. The minimum deflection was observed in the group of spiral wrapping with a tendency to bear more loads as well. Being continues wrapping scheme obtained in the scheme of spiral wrapping the stiffness across the height of the column samples were intact which helps them to bear more load with less deflection by suspending the local buckling of the samples. The values of the stiffness obtained after the experimental investigation is tabulated in the Table IV. below. 
Table IV. Stiffness of the column samples

\begin{tabular}{|c|c|c|c|c|}
\hline $\begin{array}{c}\text { Sl. } \\
\text { No. }\end{array}$ & $\begin{array}{c}\text { Column } \\
\text { Specimens }\end{array}$ & $\begin{array}{c}\text { Ultimate } \\
\text { Load } \\
\mathbf{( k N )}\end{array}$ & $\begin{array}{c}\text { Deflection } \\
\text { at Peak } \\
\mathbf{L o a d} \\
\mathbf{( m m}\end{array}$ & $\begin{array}{c}\text { Stiffness } \\
\mathbf{( k N / m m )}\end{array}$ \\
\hline 1 & CC (1) & 318 & 7.72 & 41.19 \\
\hline 2 & SHTS-HS-1L & 337 & 7.33 & 45.98 \\
\hline 3 & SHTS-HS-2L & 358 & 7.24 & 49.45 \\
\hline 4 & SHTS-HS-3L & 376 & 7.06 & 53.26 \\
\hline 5 & HTS-SP-1L & 353 & 7.19 & 49.10 \\
\hline 6 & SHTS-SP-2L & 375 & 6.94 & 54.03 \\
\hline 7 & SHTS-SP-3L & 392 & 6.70 & 58.51 \\
\hline
\end{tabular}

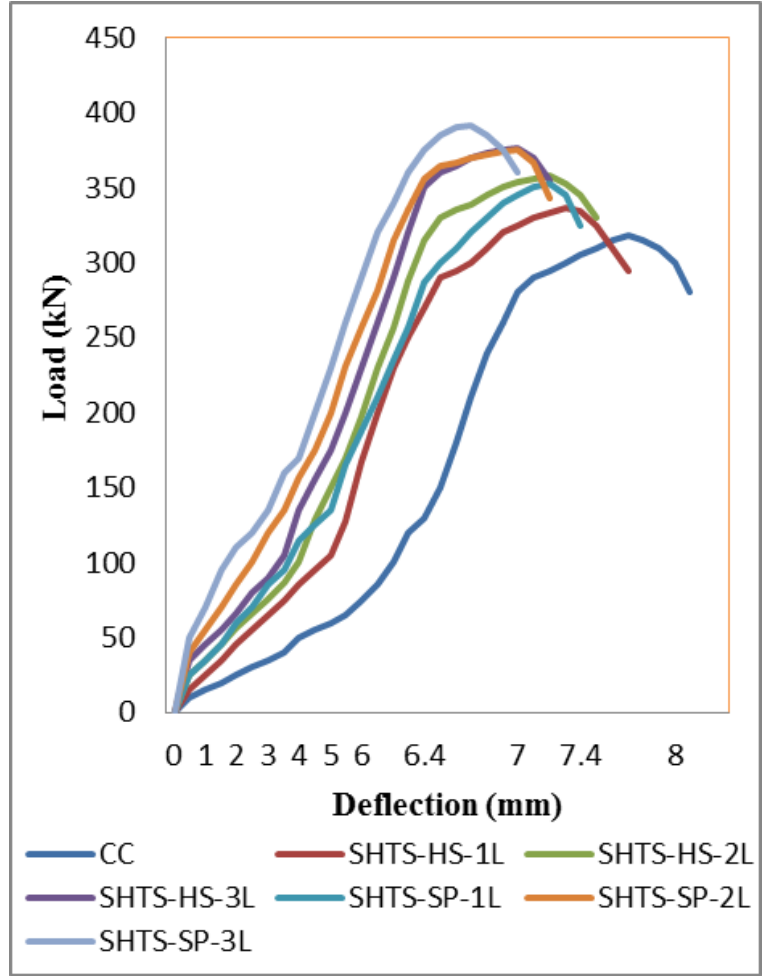

Fig. 9. Load-Deflection curve.

Due to the discontinuty in the wrapping of the horizontal AFRP strips, the stiffness obtained in those case (horixzontal wrapping) was not uniform across the whole length of the column specimens. Even tough the stiffness increased than the control samples, in the case of horizontal enfolding the column samples failed due to premature failing load unlike the samples of spiral wrapping. This is due to the diffenence in buckling in wrapped and unwrapped portions in horizontal strippings. On the other hand in both the group of horizontal and spiral wrapping, the stiffness ioncreases with the increse in the number of layers of AFRP sheets with the decrement of vertical deflection. The maximum stiffness was obtained from the Spiral wrapping of three layers. To show the variation of stiffness along all the column samples including the control specimen, a graph has been plotted in Figure 10.

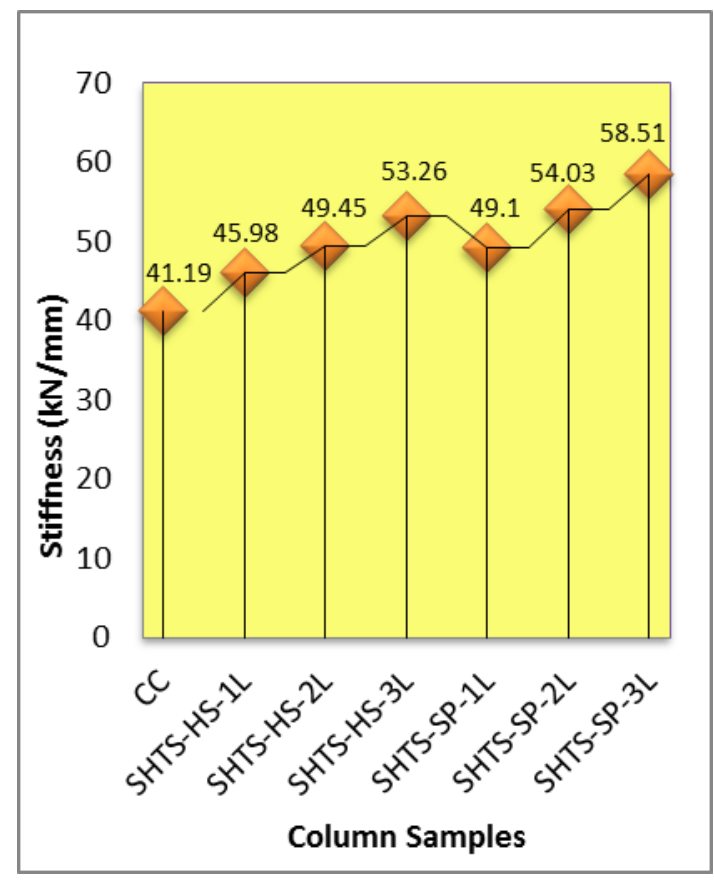

Fig. 10. Stiffness curve.

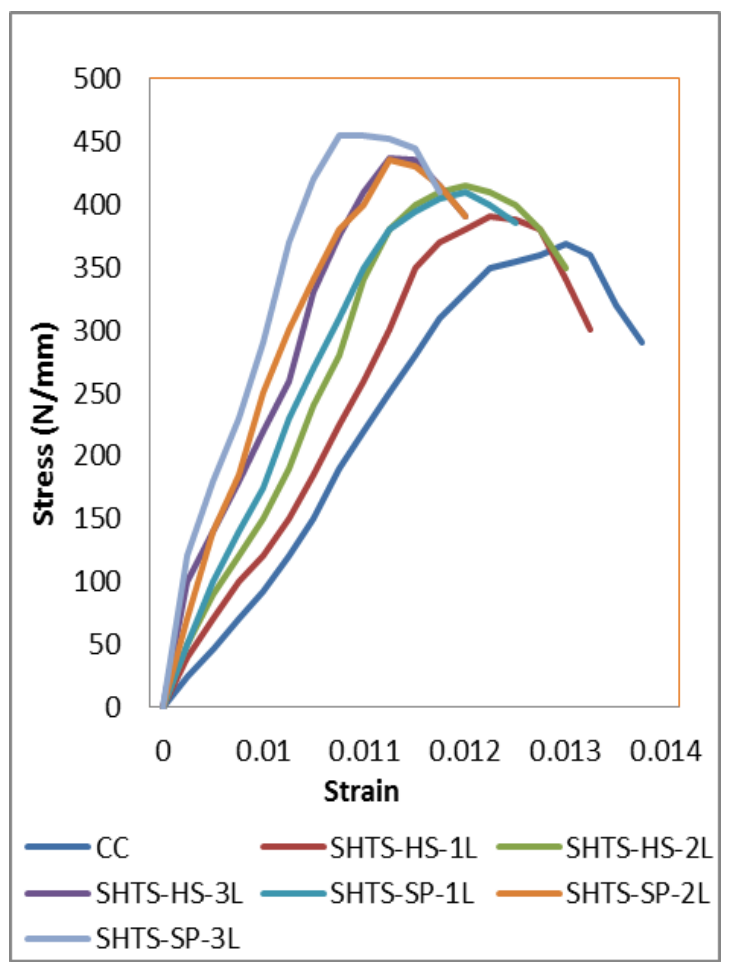

Fig. 11. Stress-Strain curve.

\section{Stress-Strain Behavior for Axial Loading.}

Axial stress-strain behavior was studied to understand the elastic properties of the column specimens in terms of Young's modulus. The stress-strain curve was plotted in Figure 11. From the diagram it can be easily notice that the strain also was getting reduced with the increase in the number of layers of AFRP coatings and in the case of spiral wrapping as well with compare to horizontal wrapping. All the column samples deport themselves elastically up to an approximate stress of $320 \mathrm{~N} / \mathrm{mm}^{2}$. 


\section{Behavior of AFRP Composite and its Practical Aspects in the Invigoration of Structural and Materialistic Properties of Corroded SHTS}

As the deflection of the specimens was getting reduced in spiral wrapping and with the increase in the number of layers as well, the stain values were also got reduced for the same. As the stress is amassed with a reduction in the value of strain it can be effortlessly said that the elastic modulus of the samples were also snowballing. In the overall experimental result, the uppermost value of elastic modulus was obtained in SHTS-SP-3L. The behavior in the axial deformation was also observed better in the case of spiral coatings and with the increase in the number of layers of AFRP strips.

\section{Ultimate Load Bearing Capability}

The variation in the ultimate load carrying capacity of all the column specimens is shown in the Figure 12. The prime reason for retrofitting a structure is to improvise the materialistic properties of the structure so that the structure redeems its identifiable strength to transmit more loads in future and to make it in working order.

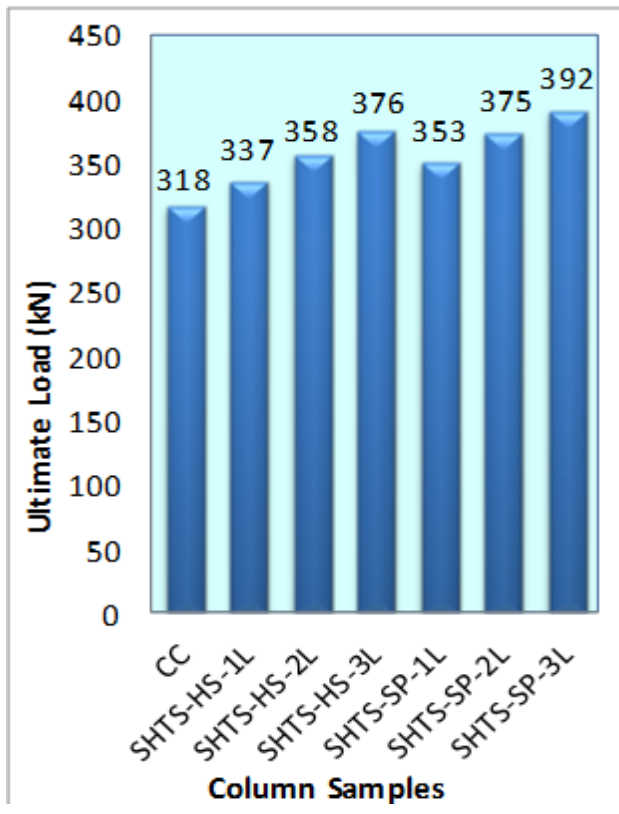

Fig. 12. Ultimate load of SHTS sections

The ultimate load carrying capacity of the column specimens were showed above in Table III and also the percentage of increment in load bearing capacity with respect to control samples.

After applying third layer of AFRP in horizontal group the strength of SHTS-HS-3L has been increased by $5.03 \%$ from SHTS-HS-2L and $11.57 \%$ from that of the SHTS-HS-1L. On the other hand in the group of spiral wrapping, the strength of SHTS-SP-2L was boosted by $6 \%$ from that of the SHTS-SP-1L and the strength of SHTS-SP-3L was increased by $4.5 \%$ from that of the SHTS-SP-2L and $11.05 \%$ from that of the SHTS-SP-1L. Now, if we broadly compare with the load bearing capacity of the two groups of horizontal and spiral wrapping, we can able to see that, the strength of SHTS-SP-1L was increased by $4.75 \%$ from SHTS-HS-1L. Similarly in compare with the two layers of both horizontal and spiral wrapping the strength of SHTS-SP-2L was more by $4.75 \%$. The strength in the case of third layer is also the same but the increment in the load carrying capacity for SHTS-SP-3L from SHTS-HS-3L was $4.26 \%$. Thus undoubtedly it can be said that the continues stiffness across the length of the SHTS that was obtained due to the technique of spiral wrapping shows better result with compare to the horizontal wrapping.

From the catastrophic behavior of the column samples, it has been noticed that, there was no detachment in the bonding of the AFRP strips from the column surfaces during the entire loading session, until the failure raised with local buckling and the fiber rapture. This proves that the captivity provided by the AFRP to immense the stiffness of the entire composite section of columns was high and great. It also has been noticed from all the experimental explanations and observations, that the behavior in the axial compression of the strengthened column samples improved with the upsurge in the number of layers as expected.

\section{CONCLUSIONS}

Application of AFRP in the strengthening of SHTS gives a positive result in increasing the overall materialistic properties of the specimens along with load bearing capacity as well. Thus the introduction of AFRP in strengthening of any materials and any structural elements will be worthy for all the above discussed maters. It has been observed that the application of AFRP prevents the local buckling by providing enormous stiffness which is obtained by the polymerization effect of AFRP with the epoxy resin. Thus in the field of aeronautical and aerospace engineering the strengthening of pressure vessels for preventing the external buckling of pressure cylinders for inward gas pressure is also a good idea. As AFRP is mostly an inert element, it can be used in any conditions unlike other FRPs. But the behavior of AFRP after polymerization is brittle in nature. Tough it can carry a huge load, it may make the structural element more ductile but itself will fail in a brittle manner mostly by making some metallic sound. Thus the prior information regarding the deterioration of the AFRP cannot be obtained visually. In the field of automobile and mechanical engineering, AFRP can play a better role in increasing the load hoisting capacity of ant materials where the profile of the structure is complex, as it can be easily bonded in any shape and profile. Regarding the strengthening of any material, the composite action of both AFRP and epoxy resin can able to play a vital role. The experimental investigation and the results obtained in this research established these following conclusions.

- The application of AFRP develops the axial distortion of the samples to endure more loads with the upsurge in the number of AFRP coatings.

- AFRP also delayed the local buckling of the column specimens by increasing the stiffness and the elastic modulus of the SHTS.

- Strengthening and retrofitting of any structural elements with AFRP also can reduce the additional self-weight of the structure unlike any other conventional methods.

- The ultimate load carrying capacity and stiffness of SHTS-SP-3L was increased by $23.27 \%$ and $42.05 \%$ from that of the control sample. 
- Owing to achieve a continues bond across the length of the specimens in the case of spiral wrapping, more stiffness was attained which leads the column specimens of spiral casing group to carry more loads then the column grouped in horizontal wrapping.

- The strength of the SHTS-HS-3L was increased by $11.57 \%$ from that of the SHTS-HS-1L and the load bearing capability of SHTS-SP-3L was increased by $11.05 \%$ with compare to SHTS-SP-1L. Thus from this point of view we can conclude that the increase in the number of layers of AFRP, increased the stiffness of the column specimens to carry more loads by deferring the upright deflection and local crumpling.

- The best performance of SHTS was observed in SHTS-SP-3L with the comparison of control specimen. The ultimate load carrying capacity of SHTS-SP-3L was increased by $23.27 \%$ and also it has been noticed that the axial deformation was also reduced by $15.22 \%$ with compare to the control specimen. Thus in overall prospective, the column samples jacketed with spiral wrapping proves worthy in the better performance as compared to the horizontal wrapping in the firming of the column specimens.

- The cost of AFRP being lesser than other high modulus FRPs attests worthy to use it in any solidification purposes.

- Being a light weight and stretchy in nature, AFRP can be easily caste off in any multifaceted profile, but the polymerization of AFRP with the intermingling of epoxy and hardener also plays a vibrant role in increasing the strength of the elements.

- Thus the introduction of AFRP in the overall improvement of the materialistic properties of SHTS gave a better impression.

\section{REFERENCES}

1. Sreedhar Kalavagunta, Sivakumar Naganathan and Kamal Nasharuddin Bin Mustapha, "Proposal for design rules of axially loaded CFRP trengthened cold formed lipped channel steel section", Thin-Walled Structures 72 (2013), pp. 14 - 19, June 2013, 0263-8231/\$, doi: 10.1016/j.tws.2013.06.006.

2. Nabajyoti Modak and S. Sivasankar, "Axial Behavior of Corroded CHST Members Confined with AFRP Sheets", International Journal of Recent Technology and Engineering (IJRTE) ISSN: 2277-3878, Volume-8 Issue-2, July 2019, pp. 5791 - 5798.

3. J. Zeghiche and K. Chaoui, “An experimental behavior of concrete-filled steel tubular columns", Journal of Construction Steel Research 61 (2005), pp. 53 - 66, June 2004, 0143-974X/\$, doi: 10.1016/j.jcsr.2004.06.006.

4. Zhong Tao, Brian Uy, Lin - Hai Han and Zhi-Bin Wang, "Analysis and design of concrete-filled stiffened thin-walled steel tubular columns under axial compression", Thin-Walled Structures 47 (2009), pp. 1544 1556, June 2009, 0263-8231/\$, doi: 10.1016/j.tws.2009.05.006.

5. K. Abedi, A. Ferdousi and H. Afshin, "A novel steel section for concrete-filled tubular columns", Science Direct, Thin - Walled Structures 46 (2008), pp. 310 - 319, October 2007, 0263-8231/\$, doi: 10.1016/j.tws.2007.07.019.

6. Kambiz Narmashiri, Mohd Zamin Jumaat and N. H. Ramli Sulong, "Shear strengthening of steel I-beams by using CFRP strips", Scientific Research and Essays Vol. 5(16), pp. 2155-2168, August, 2010, ISSN 1992-2248.

7. X. Wang, M. D. Li and Z. Y. Yu, "Self-Strengthening research of fiber reinforced Pressure vessel with metallic Liner", Journal of REINFORCED PLASTICS AND COMPOSITES, Vol. 20, No. 16/2001, DOI: 10.1106/PGRF-258J-0B5R-D58V.

8. Prof. V. L. Kadlag and Akshay Hire, "A Review on Application of Fibre Reinforced Polymer Composite in Automotive Industry”, International Journal of Advanced Research in Electrical, Electronics and
Instrumentation Engineering, ISSN (Print): 2320-3765, ISSN (Online): 2278 - 8875, Vol. 6, Issue 5, May 2017, pp. 3726 - 3729, DOI:10.15662/IJAREEIE.2017.0605089.

9. Medhavi Sinha and S. N. Pandit, "Design and Burst Pressures Analysis of CFRP Composite Pressure Vessel for Various Fiber Orientations Angles”, ISSN-2319-1120 /IJAEST, Volume 1, Number 1, pp. 35 - 40.

10. Sarada Prasad Parida and Pankaj Charan Jena, "Design and Finite Element analysis of Thick walled Laminated Composite Pressure Vessel", International Journal of Innovative Technology and Exploring Engineering (IJITEE) ISSN: 2278-3075, Volume-8 Issue-10, August 2019, pp. 4389 - 4394.

11. Chao Hou, Lin - Hai Han and Xiao - Ling Zhao, "Full - Range analysis on square CFST stub columns and beams under loading and Chloride corrosion", Thin - Walled Structures 68 (2013), pp. 50 - 64, March 2013, 0263-8231/\$, doi: 10.1016/j.tws.2013.03.003

12. Indian Standard: 1161 1998, Steel Tubes for Structural Purpose.

\section{AUTHORS PROFILE}

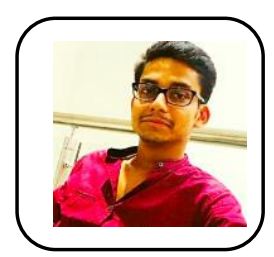

Mr. Nabajyoti Modak, Working as an assistant professor in CIVIL Engineering department of Anand Institute of Higher Technology, Chennai, Tamil Nadu, India. He completed B.E. CIVIL Engineering from Sathyabama Institute of Science and Technology (Deemed to be University) and M.E. Structural Engineering from Anna University. He is interested in structural engineering and research woks. His area includes concrete and steel structures, strengthening and retrofication of concrete and steel structures, polymer resin concrete, Polymer composites, composite structures and their applications. He is having a teaching experience of one year. He guided $7 \mathrm{BE}$ projects and one ME project. He is a member of IFERP, life time member of ICSES and IAENG.

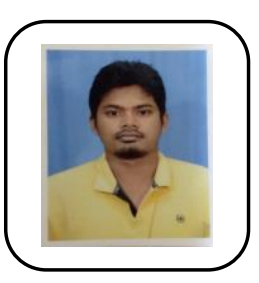

Mr. Durlab Das, Completed his M. Tech in Aeronautical Engineering from Hindustan Institute of Technology and Science (Deem to $\mathrm{Be}$ University) and B.E in Aeronautical Engineering from Anna University. He is having interest in composite materials and their strengthening with FRP

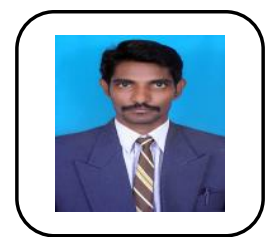

Mr. R Vinodh Kumar, Working as an Assistant Professor in Meenakshi College of Engineering, Chennai, Tamil Nadu, having 6 years of teaching experience and 4 years of industrial experience. He completed his ME Structural Engineering from Annamalai University. He guided six ME projects and $35 \mathrm{BE}$ projects. He is having interest also a member of ISTE. in concrete technology and research work. He is 